\title{
The Livelihoods of Micro and Small Enterprise Operators in a District of Addis Ababa, Ethiopia: Reflections on their Capital Assets Reality \\ Mulugeta Yohannes*
}

\begin{abstract}
The Sustainable Livelihoods Framework (SLF) presupposes the outcomes of any livelihood strategy, including working in micro and small enterprises, the results of interplay of context, access to and level of different sorts of assets, and policies and institutions. Targeting those MSE operators working in Woreda 1 of Lideta sub-city of Addis Ababa and based on qualitative data generated via in-depth interviews, key-informant interviews, and focus group discussion, this paper aims at assessing the level and access of micro and small enterprise operators to various types of capital assets. It was found that the operators have relatively better access to different levels of social, political, and human assets. In addition to the high level of access to and possession of these three types of assets, it is also uncovered that the operators possess a remarkable amount of financial and physical assets. To further augment these capital assets, the study mainly proposes alleviating the market shortage, improving provision of public infrastructure and facilities, availing affordable credit and enhancing the capacity of the operators.
\end{abstract}

Keywords: Livelihoods, Sustainable Livelihoods Framework, Micro and Small Enterprises, Capital Assets

DOI: http://dx.doi.org/10.4314/ejbe.v4i1.1

\footnotetext{
*Mulugeta Yohannes Lecturer, Department of Public Administration and Development Management, College of Business and Economics, Addis Ababa University. PhD Candidate, School of Economics and Management, Tilburg University, The Netherlands. Email: mulugetayohannes1@gmail.com Mob. +251-911-092445, P. O. Box 150445 Addis Ababa, Ethiopia.
} 
The Livelihoods of Micro and Small Enterprise Operators

\section{Background and Intent of the Study}

In most developing countries, entrepreneurial activities and the associated Micro and Small Enterprises (MSEs) are particularly salient among the urban poor. These enterprises provide employment opportunity and source of income, by which these poor people withstand causes and seeds of extreme poverty. Consequently, encouraging and supporting the establishment and expansion of Micro and Small Scale Enterprises (MSEs) is one of the development paths opted by the governments of developing countries to reduce unemployment and the resultant poverty (Daniels and Mead: 1998). Governments of various least developed nations are allocating ample resources for promoting the MSE sector because they see MSEs as engines of employment, tools of alleviating poverty and improving equality (Gomez:2008).

The government of the Federal Democratic Republic of Ethiopia (FDRE) has employed the promotion and development of MSEs as a strategy that can have a profound effect on reducing urban poverty, creating employment opportunity and bringing about overall growth in the business sector( Tegegne and Meheret, 2010). Moreover, the development of micro and small businesses has been also considered as a vehicle to reduce poverty and create jobs for the increasing number of graduates from technical and vocational training institutions. Accordingly, the government has allocated and spent huge amount of resources for the expansion of the MSE throughout the country (Tegegn and Meheret, 2010) and even intends to spend more in the coming years of the actualization of the Growth and Transformation Plan (GTP) from 2010/112014/15 (MoFED, 2010, Zemen, 2011). 
After the adoption of the country's Micro and Small Enterprises Development Strategy, many such enterprises have been established and created job opportunity for a significant number of unemployed urban poor throughout the country. For instance, by citing the Ethiopian Ministry of Works and Urban Development (MWUD) (2009), Tegegne and Meheret (2010) reported that 395,806 employment opportunities have been generated by the 71,568 MSEs created in four major regions of the country namely Oromia, Amhara, Southern Nations, Nationalities and Peoples Region, and Tigray.

The success or failure of MSEs, hence their ability in enhancing the quality of life of their operators, is dependent on a number of factors. Consequently, this condition implies a view that the detailed understanding of the poverty reduction role of MSEs and their livelihoods impact is possible by employing an approach that embraces all issues and variables that affect them. While duly pointing at such a tool, Degefa (2010) asserted that a framework named Sustainable Likelihoods Framework (SLF) permits the depiction of a situation in which a given context, access to different assets, policies and various local institutions affect people's livelihood activity, in this case working in MSEs, and the outcomes of the same activity. In close resemblance with the above opinion of Degefa, Meron (2005) claimed that the Livelihoods Approach to poverty reduction provides a broadened understanding of the various factors that restrict or enhance livelihood opportunities.

As a matter of fact and in line with the above ideals of the SLF, these MSEs and their operators are constrained or supported by a variety of factors related to the wider political, economic, social, and environmental contexts. The 
possession and access to various sorts of capital assets, along with policies and institutions, are also among the main determinants shaping the livelihoods outcomes of this livelihood strategy. Currently existing researches, as reviewed in the next sub-section, do not adequately study the asset condition of MSE operators. Most importantly, there is paucity of literature on how networks of financial, human, social, physical and political assets are affecting the livelihoods of MSE operators. This paper, which focuses on the assessment of access to and control of various sorts of capital assets, is extracted from the comprehensive study on the livelihoods reality of micro and small enterprise operators engaged in metal and wood work activity in Woreda ${ }^{1} 01$ of Lideta sub-city of Addis Ababa. ${ }^{2}$

To this end, this article is organized in five parts. The first part introduces the research. Part two provides a brief snapshot on related concepts, existing studies on the matter under investigation, and lastly the analytical framework. Part three is about the methodology of the research and description of the study area. Thorough discussion of the livelihoods reality, in this case the access to and control of different types of capital assets, of the operators are dealt with in the fourth part. The last part makes conclusions and forwards some preliminary suggestions based on the findings of the study.

${ }^{1}$ The current lowest unit of local government to form a sub-city- an arrangement peculiar to Addis Ababa city.

2 The original research, on which this article is based, was undertaken as part of MA degree at Addis Ababa University, Ethiopia in 2011.

EJBE Vol. 4 No. $1 / 2014$

Page 4 


\section{Conceptual and Analytical Framework}

\subsection{Micro and Small Enterprises (MSEs): What They Are}

Coming up with a universally applicable definition of MSEs is found to be difficult (Storey, 1995, cited in Kayanula and Quartey, 2000). This is so because the criteria and ways of categorizing enterprises as micro, small and medium vary from country to country and from organization to organization. The absence of such uniform definition of MSEs has created a difficulty. In line with this, for instance, Tegegne and Meheret (2010) argued that the absence of a single or globally applicable definition has made the task of counting the number of MSEs and assessing their impact extremely difficult across countries.

In the case of Ethiopia, too, there is lack of uniform definition at the national level. While the definition by Ministry of Trade and Industry (MTI) uses capital investment, the Central Statistical Agency (CSA) uses employment and favors capital intensive technologies as a yardstick. The definition used by MTI, which uses capital investment as a yardstick, was developed for formulating micro and small enterprise development strategy in 1997. According to the MTI, micro enterprises are those business enterprises, in the formal and informal sector, with a paid up capital not exceeding Birr 20,000 and excluding high tech consultancy firms and other high tech establishments. Small enterprises are those business enterprises with a paid up capital of above Birr 20,000 and not exceeding Birr 500,000 and excluding high tech consultancy firms and other high tech establishments. On the other hand, CSA categorizes enterprises into different scales of operation on the size of employment and the nature of equipment. To CSA, establishments employing 
less than ten persons and using motor operated equipment are considered as small scale manufacturing enterprises. Enterprises in the micro enterprise category are subdivided into informal sector operations and cottage industries. Cottage and handicraft industries are those establishments performing their activities by hand and using non-power driven machines where as the informal sector is defined as household type establishments or activities, which are non registered companies and cooperatives operating with less than 10 persons. All enterprises employing ten or more workers are grossly considered as medium and large enterprises (CSA: 1999b and 2000 cited in Tegegne and Meheret: 2010; MTI: 1997). For the purpose of this study, CSA's definition is employed.

\subsection{Brief Review of Previous Studies}

Literature on the capital asset reality of MSEs and, specifically, how the nexus between such assets affect the livelihoods of their operators is scanty. Most of the existing studies, instead of primarily investigating the status of MSEs in relation to numerous types of assets, attempt to treat the above concern as part of their effort in assessing the impact of micro finance, or the major constraints facing the sector. Below is a synopsis of these researches.

It is widely argued that money earned from numerous income generating activities, loan, credit and remittances are considered as FC (Rakodi, 2002, Degefa, 2010). The facilitative role of MSEs in increasing the level of CF of their operators is well-documented. For instance, according to Green et al. (2006), working in such ventures enhances sustainable livelihoods, as it improves the access of the poor to various financial resources secured from 
formal and informal sources. On the other hand, level and access to finance was empirically proved to be one of the factors shaping the role of MSRs in poverty reduction in the Tanzanian capital, Dar es Salaam (Maliti and Mnenwa, 2008). Similarly, another longitudinal study explicitly revealed that finance was the key determinant of the long-term survival and viability of MSEs in five major cities of Ethiopia (Eshetu and Zeleke, 2008).

MSEs have an augmenting effect on their operator's capability (human capital) by ensuring better access to health and education (Daniel, 2007, Getahun, 2009). Human capital in the form of possessing managerial and technical skills was indicated as a variable determining the survival of MSEs (Eshetu and Zeleke, 2008). MSEs are also sources of entrepreneurial spirit, capacity and skill (Adeyemi and Aremu, 2011). One study showed that MSE operators' productivity is hampered significantly by low human capital caused by lack of training (Getahun, 2009).

There are few researches disclosing the role played by SC on the livelihoods of MSE operators. For instance, participation in social networks such as Iqub contributes to the viability of MSEs (Eshetu and Zeleke, 2008). Financial resources generated from indigenous social networking such as Iqub served as the major source of initial capital for women-owned MSEs (Paul and Rahel, 2010).

\footnotetext{
${ }^{3} \mathrm{~A}$ voluntary, informal and indigenous form of rotating saving and credit scheme, where members contribute a mutually agreed amount of money to a common pool on a regular basis and collect the funds by drawing lots or by other means on weekly or monthly basis.
} 
Assets falling under the category of PC are physical and social infrastructures such as housing, road, transport, schools, and health facilities. It also includes tools, equipment, and utensils owned and used by people (Farrington et al: 2002, Rakodi, 2002). Writers such as Payne (2002) incorporate urban land under this asset. Inadequate infrastructure such as water and roads is among the challenges that Nigerian MSEs have faced (Adeyemi and Aremu, 2011). There are also other studies revealing instances where MSEs have provided better housing to their operators and their families in Ethiopia (Daniel, 2007), and in the urban centers of four western African countries namely Benin, Burkinafaso, Niger, and Togo ( Roy and Wheeler, 2006).

Unlike the above-reviewed studies and other related works, this article which specifically strives to assess the level and situation of capital assets is drawn from the broader research that attempted to qualitatively appraise the overall livelihoods condition of MSE operators in a holistic manner.

\subsection{Livelihoods}

The different meanings of livelihoods given by various writers are not mutually exclusive, as all commonly address and emphasize capital assets and income earning activities. For instance, Rigg (2007, p.77) wrote that a livelihood is the way that a household or an individual gets by. Similarly, Ellis (1999, p.2) wrote that the activities, the assets, and the access towards them jointly determine the living gained by an individual or household. A livelihood is, therefore, about money, food, labor, employment and assets. Likewise, the International Food Policy Research Institute (IFPRI) (2002) underscored that livelihoods are composed of human capabilities, assets, and means of income 
and living. Similarly, livelihood refers to the group of activities that a household or an individual regularly carries out and the entitlements it claims in order to support and prolong a given standard of living (Dessalegn and Aklilu, 2002, cited in Meron, 2005). In few words, a livelihood comprises and denotes to the capabilities, assets (encompassing both material and social resources) and activities required for a means of living.

Equally to livelihoods, its 'sustainability' has been also conceptualized by numerous scholars, all stressing the need for prudent resource utilization while ensuring intra-generational and inter-generational equity. In connection with this, while elaborating sustainable development, Meikle et al. (2001, pp. 11-12) by citing Chambers and Conway (1992) explained that:

A livelihood is sustainable when it can cope with and recover from stress and shocks, maintain or enhance its capabilities and assets, and provide sustainable livelihood opportunities for the next generation; and which contributes net benefits to other livelihoods at the local and global levels and in short and long term' as well.

\subsection{The Sustainable Livelihoods Framework}

Developed first by the United Kingdom's Department for International Development and its partners, the Sustainable Livelihoods Framework (SLF) was devised originally as a tool to analyze rural development problems and informing the planning of interventions targeted towards poverty reduction (Lloyd-Jones and Rakodi, 2002). Livelihoods, in the SLF, besides income, encompasses:

EJBE Vol. 4 No. $1 / 2014$

Page 9 
The Livelihoods of Micro and Small Enterprise Operators

the capabilities, assets (including both material and social resources) and activities required for a means of living. A livelihood is sustainable when it can cope with and recover from stresses and shocks and manage to enhance its capabilities and assets both now and in the future, while not undermining the natural resource base (Chambers and Conway: 1992 cited in Meikle et al: 2001, pp. 400).

Although SLF was initially designed for application in rural settings, nowadays it is becoming popular to understand the livelihoods of poor people in urban areas of developing countries of Africa, South Asia and Latin America (Degefa, 2010). SLF, as an analytical framework, focuses attention on the assets that poor men and women use, and the strategies they employ to make a living (Ibid).

Some of the salient features of SLF that make it to be widely used in assessing the livelihoods reality of the poor are acknowledging the multi-faceted nature of poverty; recognizing that the poor develop diverse and changing livelihood portfolios addressing their perceptions of their own poverty, but do so within the context of pervasive vulnerability; drawing on (and replenish) capital assets; and having the success of their strategies facilitated or impeded by a range of policies, institutions and processes (PIPs) (Degefa:2008, Farrington et al, 2002).

Many writers in the area of urban livelihoods agree that SLF is an appropriate tool in finding out how a nexus of factors such as context, access to and possession towards various types of assets, government policies and grassroot 
level authorities influence, either positively or negatively, people's livelihood activities and the resultant outcomes (Degefa, 2010; Lloyd-Jones and Rakodi, 2002). In both urban and rural settings, the key elements of the SLF are: Vulnerability Context, Assets, Policies, Institutions and Processes (PIPs), Livelihood Strategies, and Livelihood Outcomes.

Vulnerability Context: This refers to the insecurity or well being of individuals or communities in the face of changing environments (ecological/social/economic/political) in the form of sudden shocks, long term trends or seasonal cycles (Mosser: 1996, cited in Meikle et al., 2001). The degree of vulnerability relates both to the level of exogenous threats to a household's, individual's or community's wellbeing and to their resilience to withstand and recover from these external threats (ibid).

Capital Assets: These are the resources on which people draw in order to carry out their livelihood strategies. These assets include a broad range of financial(in the form of credit, remittances, cash, savings and pensions); human capital or sometimes termed as capabilities (skill, education, experience, training, being healthy); social and political capital (whose attributes are social and political networks, membership and access to various social and political groups, relationships of mutual trust and reciprocity. It should be noted here that there are writers like Baumann and Sinha (2001) cited in Farrington et al. (2002) who recognize political capital as a distinct type of asset); physical capital (mainly consisted of physical infrastructure like transport, housing ,energy) and lastly natural capital, which incorporates land, water, forests and other stocks commonly used.

EJBE Vol. 4 No. $1 / 2014$ 
The relative importance of these categories of assets varies between urban and rural areas. For instance, financial, human and physical assets are more critical in urban settings whereas more natural capital is highly crucial in rural areas than urban (Meikle, 2002). Assets are not always owned by the men and women who use them in their livelihood strategies - rather, they may have varying extents of access to and control over these assets. Issues such as access to assets and how the access of urban poor can be improved is a key concern in SL model (Degefa, 2010, Lloyd-Jones and Rakodi, 2002, Meikle et al, 2001).

Policies, Institutions and Processes (PIPs): Practically, they denote to institutions (established ways of doing things, such as social norms and belief systems); organizations that can be public, private, non-governmental and community based; and policies or legislation. They are relevant at all levels, from households to international. They are key in determining access to the various types of capital assets that the poor people use in pursuing their livelihood strategies either through acting as conduits to make assets available to them, or as hindrance to their access (Lloyd-Jones and Rakodi, 2002).

Livelihood Strategies: These are the planned and deliberate activities on which people are engaged to build their livelihoods. Mostly they consist of numerous activities targeted to build asset bases and access to goods and services for consumption. Livelihood strategies include coping strategies designed to respond to shocks in the short term, and adaptive strategies designed to improve circumstances in the long term. Livelihood strategies are determined by the assets and opportunities available to and accessible by men 
and women (which are in turn affected by PIPs and changes in the vulnerability context) as well as by the choices and preferences of the poor (Degefa, 2010).

Livelihood Outcomes: As the term itself indicates, these are:

the ultimate results of women and men's livelihood strategies and feedback into the vulnerability context and asset bases, with successful strategies allowing them to build asset bases as a buffer against shocks and stresses, as opposed to poor livelihood outcomes which deplete asset bases, thereby increasing vulnerability. Livelihood outcomes may therefore lead into either virtuous or vicious cycles (Meikle et al., 2001).

By the same token, Degefa (2010) argued that the final outcomes of any livelihood strategy can be desirable or undesirable depending on how the above-shown five elements of SLF interact with each other. The hypothetical model of SLF is shown diagrammatically below.

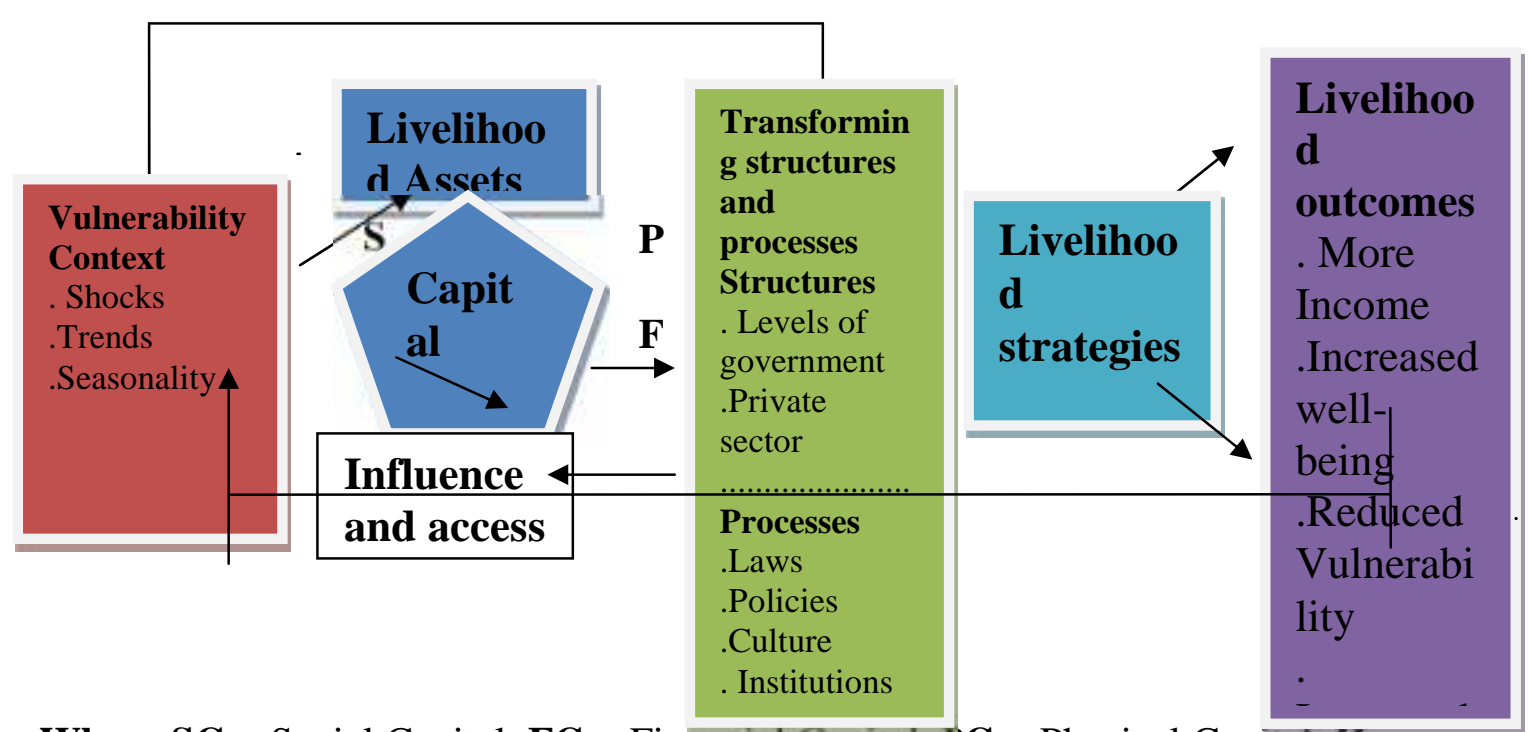

Where $\mathbf{S C}=$ Social Capital, $\mathbf{F C}=$ Financial Capital, $\mathbf{P C}=$ Physical Capital, $\mathbf{H}$

= Human capital and $\mathbf{P C}^{\prime}=$ Political Capital 
The Livelihoods of Micro and Small Enterprise Operators

The DFID Sustainable Livelihoods Framework: Adopted from Rigg (2007)

\section{Methodology and the Study Area Profile}

The methodology employed for this research is the qualitative approach based on intensive fieldwork data collected through different techniques. The justifications behind opting for this approach are given below:

1. It is argued that the goal and means of any urban poverty reduction intervention, including MSE program, must be sustainable livelihoods. In line with this, again, proponents of MSEs stress that establishing and running MSEs is a prime way of enhancing sustainable livelihoods. In short, as the aim of this study is to analyze the overall livelihoods condition and impact of MSEs by attempting to explore the deep livelihood-related experience of owners of MSEs, the underlying factors behind establishing and being engaged in MSEs, and the livelihoods impact of the same, the researcher has opted to employ the qualitative methodology. Similarly, in his research in which he assessed the level and access to various capital assets, the livelihood activities, and the food security situations of the two impoverished communities in the Ethiopian capital, Addis Ababa, Degefa (2010) also used purely qualitative methodology. 2. In order to better understand the existing life reality of the MSE operators and the impact of MSEs on their operators, one has to rely and focus on the detailed analysis of the experience, value, perception, priority, etc of the operators. Collection of data in such details can be better handled by the qualitative methodology. Synonymously, other writers argued that qualitative methodology enables researchers to collect data, in a detailed fashion, about aspects such as understanding of human perception, value, attitude, experience, 
behavior, and the reasons that govern such behavior (Crang and Cook:2007, Meron : 2005).

\subsection{Data Collection Techniques}

For triangulation purpose, this research has utilized a variety of data gathering tools. In addition to Informal Conversations held with some of the targeted operators during and after lunch break on different issues, structured openended interviews, key Informant Interviews, Focused Group Discussion, and Non-participant Observations were employed to gather primary data. Primary data generated via different tools were further substantiated by a critical review of secondary sources like books, articles, magazines, brochures and published and unpublished materials.

\subsection{Sampling Strategy and Procedure}

The Lideta sub-city of Addis Ababa city is purposely chosen, among the 10 sub cities of Addis Ababa. This is due to the fact that it is a sub city where there is persistent poverty and high unemployment. In the former case, the sub city has the highest proportion of households under the relative poverty line (53\%), making it the most impoverished part of the capital (Netsanet: 2009, Yared: 2010). In relation to unemployment, again this sub-city (where the unemployment rate is $26.2 \%$ in 2007, according to CSA: 2010) ranks only the second. In 2007, the same source documented that the first and third highest rate of unemployment is registered in Addis Ketema (27.2 \%) and Arada Sub cities respectively.

Woreda 1, among the woredas of the Lideta sub-city, is again deliberately selected for the study. The reason for choosing it is that, according to the 
official and experts of Lideta sub-city MSEDO, in terms of performance, the metal and wood work cluster named Sahlu Chaka, is rated as the most successful at the sub-city level. This cluster is found at Woreda 1.

Although there are different activities or sectors in which the MSE operators have been engaged in Woreda 1 of Lideta sub-city, the one selected for this research is the metal and wood work sector because of the following rationale:

$>$ There are 20 cooperative associations working in this sector, whose share in terms of membership is much more than other cooperatives working in other sectors. This has convinced the researcher to realize that it is possible to generate substantial data from this sector. The sector's 'popularity' in absorbing significant number of operators is also proved empirically by Meheret and Tegegne (2010). Besides, according to the official and experts of Lideta sub-city MSEDO, in terms of performance, this sector is placed at the top. Based on this, the researcher concluded that the lesson and experience drawn from the detailed study of this relatively successful sector can help the concerned bodies in improving the performance of other sectors.

Those cooperative associations engaged in this sector are located in one cluster at Woreda 1 of the sub-city. This made the sector more and easily accessible to the researcher.

According to experts of the woreda MSEDO, there are 20 cooperative MSEs that are engaged in the manufacturing of wood and metal products that have provided a permanent job and hence income generation opportunity for a total 
of 214 members. Therefore, these 214 operators are the target population of the study from which 20 individual operators were taken as samples. One operator from every cooperative MSEs was interviewed in detail. Responsibility within the MSEs, number of years of working in the MSEs, age and gender are some of the issues taken into account while selecting the interviewees for the detailed interviews. In addition to the interviews, three hours-lasting focus group discussion (FGD) was also held, mediated by the researcher. Participants of this FGD were selected based on criteria of gender, age, and duration or length of membership. However, those operators contacted through the in-depth interviews were excluded from being participant of the FGD.

\subsection{Data Analysis}

After the fieldwork was completed, the collected data was duly transcribed manually. Then, the transcribed raw data was categorized into different predetermined codes. These pre-determined codes are the explicit SLF components and sub-components. Therefore, most part of the analysis is done thoroughly in light of the SLF. Uniquely informative and demonstrative statements by the respondents are included in order to substantiate what has been commented on and discussed before.

\subsection{The Study Area Profile}

The Lideta sub-city is one of the 10 sub-cities of the Ethiopian capital, Addis Ababa. The sub-city occupies a total area of 11 Sq.Km (Netsanet: 2009) with a total population of 201,713 in 2007 (CSA: 2010). Currently, the sub city has a total of 11 woredas. Netsanet (2009) reported that, among the 10 sub-cities of 
Addis Ababa City, this sub-city has been the one with the highest poverty incidence level (53\%) in 2008. The close assessment of housing conditions at the sub-city also reflects the same appalling image. For instance, according to the national census conducted in 2007, there were 44,351 housing units at the sub city of which 37,398 were made of wood and mud; 35,374 were over 20 years since they were constructed; 22,388 were rented from the kebele $e^{4}$ and 39, 485 units had no bathing facilities(CSA:2010). In short, the sub-city is known for being congested with slums (Netsanet: 2009). Similarly, the sub-city has also been recorded as the one where the rate of unemployment was as high as $26.2 \%$ in 2007(CSA: 2010).

\section{Discussion and Findings}

The wider context (economic, environmental, social, and political) on which the urban poor live and operate determines the assets available and accessible to them and the way of using these assets (Meikle: 2002). This empirical study also revealed that the asset level and access by the operators are the results of the prevalence of supportive context such as free market system, decentralization, federalist state structure, unemployment, price ceiling, presence of favorable policy environment and committed political leadership. However, the level and access towards numerous types of assets as well as their livelihood were constrained by context-related problems like market shortage, misconception of the society, fierce competition, inflation, high and increasing price of inputs and basic commodities, poor access to social facilities and infrastructure, tenure insecurity, inconvenient working place, and bureaucratic work procedures.

\footnotetext{
${ }^{4}$ The former name for the lowest unit of local administration, now renamed woreda.
} 
The impacts of context on livelihoods and livelihoods in turn on context are mediated by policies, institutions and processes, which themselves are outcomes of the context (David and Tacoli: 2010). Thus, as empirically shown in the main research report, a number of formal and informal governmental, non- governmental, private and commercial institutions have played helpful roles through creating better policy environment, organizing the operators to establish MSEs, credit and training provision, increasing the political capacity of members, and finally providing mutual support. Yet, some of the shortcomings associated with these institutions and with an adverse effect on the MSEs are inflexible working procedures, lack of commitment and responsiveness, and adopting unsuitable policies.

The livelihoods approach to poverty reduction echoes such thinking that the urban poor are not always asset-less. This is because although the poor are lacking cash, savings and other material assets, they are rich in possessing other non-material assets such as their health, experience, skill, training, knowledge, friends, family, and natural resources surrounding them (Rakodi: 2002). Proponents of the livelihoods approach firmly argued that there is a need to understand these assets in order to portray the various opportunities and constraints around them. Assets can be conceptualized as a stock of capital '...stuff that augments incomes but is not totally consumed in use' (Narayan and Prittchet: 1999, cited in Rakodi: 2002). Some of the features of these assets are that they can be stored, accumulated, exchanged, or get exhausted and put to work to generate income or other modes of benefit (ibid).In general, assets are categorized into financial, human, physical, social, and natural. From all these types, significance and implication of natural capital in the context of 
urban areas is supposed to be less. This was also true in the studied MSEs. Instead, another asset, namely political capital is found to be critical in relation to MSE operators.

\subsection{Financial Capital (FC)}

According to Degefa (2010), FC denotes those assets in the form of cash earned from income generating activities, savings, debit, credit and remittance income. FC in general and cash in particular is more salient in urban areas due to the highly monetized nature of urban economies (Rakodi: 2002).

During the FGD, it was found that, mainly ensuing from low and insufficient market, the operators usually suffer of shortage of cash leading to their inability to cover their daily needs adequately. The other cause of this low cash presence at the disposal of the operators could be the increasing expense incurred by their respective MSEs in relation to purchase of raw materials and services such as transportation, in addition to cost of utilities consumed both at home and work place. Few of the interviewed operators indicated that the compulsory saving also adds to this decreased amount of cash at hand. The operators frequently mitigate this problem of cash shortage through borrowing and lending from each other. The other mechanism of easing such cash scarcity is through diversification of income generating activities, as it was revealed during the informal conversations.

Only two operators informed the researcher that their parents have received remittances from their sisters who are serving as house servants in Middle East Arabian countries. These respondents further indicated that maintenance and 
improvement of their housing and purchase of household durables are made possible by the money secured from these remittance sources. With regard to pension, since majority of the operators of the studied MSEs were unemployed before, being engaged in their respective businesses, it was found that they have no income derived from pension.

Debt is of many varieties, of which one can be the one secured from raw material suppliers. Use of debt or participation in it is a common practice in the Ethiopian MSE sector (Gebrehiwot and Wolday: 2006). Nonetheless, debt of any type was found to be almost nonexistent among the studied MSEs. This is because, due to their market problem, most potential debtors such as suppliers are reluctant to extend the same to the MSE operators, according to the majority of the interviewed operators.

The presence of affordable credit is essential for enterprise growth (Meikle: 2002).With regard to credit access and availability, according to the key informants and operators, there are both formal and informal sources serving the operators in the studied area. The former consisted of loan from other fellow operators, relatives and friends, according to the operators. The credit generated from such sources, along with a loan secured from micro finance institution (MFI) and own savings, constitutes a portion of the start-up capital of the MSEs, according to one of the key informants. Most of the operators pointed out that Addis MFI is the only formal source of credit approached by the operators, though the researcher observed that there are other financial service providers like state-owned and private commercial banks in the studied area. Even if many writers such as Vandenberg (2006) and Garcia and Maru 
(2010) amplify the already established opinion on micro-finance that holds a view that micro-finance is a useful way of channeling finance to the poor and overcoming the difficulties they face in securing credit from formal financial institutions such as banks, it was reported by the operators that the terms of credit of Addis MFI are not suitable as the MFI fixes short repayment period with higher interest rate i.e. $9 \%$ in comparison with the interest rate of $6 \%$ charged by the banks. The operators indicated that the above-named MFI charges them totally $13 \%$ of the extended credit, of which $9 \%$ is paid as interest on the loan, $3 \%$ as service charge while the balance is accounted as insurance contribution. This high loan cost puts the affordability of the loan of the MFI demanded by the users. Obviously, such high loan cost further damages the already low meager revenue of the enterprises. On the other hand, the operators pointed out that the short repayment period scheduled by the MFI put them in worrisome state as they face shortage of market resulting in their inability to repay the loan within the period stipulated by the MFI. Given the market problem of the MSEs, it is fair to suggest the MFI to effectuate a 'grace period policy'.

During the FGD, it was explicated that the operators had a prior saving, though incomparable with their current level. The operators indicated that they have saving accounts opened at Addis MFI in their own name. In this regard, they appreciated the relentless effort of employees of the MFI in encouraging the operators to save through training provision and exercising an innovative and flexible modality of collecting the saving contribution of each operator as explained in the following way by one respondent during the in-depth interview 
The Livelihoods of Micro and Small Enterprise Operators

the employees of Addis MFI frequently come to our working shade and collect whatever we can give them starting from Br. 5.[28,Male, Bachelor]

It was also reported by the key informants that the operators are expected to save $30 \%$ of the monthly revenue of their enterprise in the same MFI under the name of their MSE. In addition to the above narrated forms of saving, the interviewed operators expound that there is also a scheme called Iqub, where each member of it puts monthly contribution and the pooled amount is given to each contributor on rotating basis. The money accessed from Iqub sources is usually spent for undertaking other income generating activities by other family members such as gullit. ${ }^{5}$ Such informal indigenous rotating saving and credit schemes have a remarkable role in further consolidating the already enriched social capital among the operators. On the other hand, the access to and availability of Iqub as a factor determining the long-term survival and viability of small enterprises is attested empirically in 5 main cities of Ethiopia according to Eshetu and Zeleke (2008).

To wind up, the operators had better level of cash possession in comparison with their previous life, but it is declining as time passes because of the inflation, increasing price of inputs, basic commodities and services such as transportation. Similarly, the operators more or less have no remittance, pension, and debt. The main reason for lack of the latter, especially from suppliers, is the poor availability of market. However, the studied operators were able to mobilize ample credit and saving resources from formal and non-

\footnotetext{
${ }^{5}$ A petty trading activity usually undertaken at road sides and sometimes at designated places.
}

EJBE Vol. 4 No. 1/2014 
The Livelihoods of Micro and Small Enterprise Operators

formal sources. In general, the operators have a fairly good level and access to FC.

\subsection{Human Capital (HC)}

Conceptually, $\mathrm{HC}$ refers to the skills, experience, knowledge and ability to work. Clearly FC, in terms of access to employment and earnings, is strongly dependent on adequate HC. In turn, $\mathrm{HC}$ is highly dependent on adequate nutrition, health care, safe environmental conditions, and education (Farrington et al: 2002). Accessibility to education and training provides people the opportunity to improve the value of their HC (Meikle: 2002). Though usually used together, education and training are different concepts. The fundamental point of demarcation is that education, which is the basic element in $\mathrm{HC}$, makes contribution to asset enhancement in a broad or general manner while the role of training in doing so is in a specific and more immediately applicable way ( Harper : 2002). As far as education is concerned, literacy especially basic education enhances and facilitates all other latter efforts to build HC. In the same way, the ability to access, absorb and apply all employment-related skills is dependent on the educational base of those undergoing training (Ibid). The data gathered, primary and secondary, on the educational status of the studied operators reveal that all have completed either high school level or Technical and Vocational Education and Training (TVET) education at the nearby secondary schools and colleges. According to the key informants, the fact that all of the operators are literate has facilitated the skill acquisition process during trainings organized and coordinated usually by the woreda MSEDO in partnership with other stakeholders such as St. Mary's University College, Addis Ababa Tegbare Id TVET College, Higher 4 TVET Institute and 
Productivity Improvement Center. The former provides business development, basic management and accounting trainings while the latter three conduct technical trainings. The formal education they grasped at various levels has also helped the operators to manage financial affairs wisely both at home and working place. Moreover, the operators commented that their increased literacy level impacted their political capital and decision making level positively.

The operators widely pointed out that the very nature of their work i.e. labour and energy-intensiveness of metal and wood work has made them healthy and physically strong; whereas the income derived from their engagement has helped the operators in accessing improved medical and educational facilities for themselves and their dependants. The same supportive role of MSEs in maintaining the health of operators and their families are also indicated by other researchers. For example, Daniel (2007) reported that, among the majority who visited medical facilities over the last 12 months, $86.7 \%$ of the operators responded that the source of funds for their access to medical facilities was income derived from their MSEs.

Most of the interviewed operators possess prior work experience and skill acquired via taking part in formal training programs in TVET institutions or gained as a result of working previously in similar area of engagement. Having work experience related to current activity has contributed positively to the overall performance and productivity of the operators especially by helping the operators to grasp skills fast and easily during practical training sessions, the key informants affirmed. The presence of experienced members has also allowed for and resulted in skill sharing for the less experienced members, 
which has, again, a productivity improvement effect. In the same vein to the prior experience, the fact that they are organized and working as cooperatives has boosted the negotiation and conflict solving capacity and skill of the operators. However, the operators exposed that whatever enormous are the merits of cooperative form of organizing in skill sharing, few of the operators recalled that, there are also times when conflicts are arising as the members who formed the cooperatives initially did not know each other. Accordingly, they suggested a caution must be taken while organizing cooperatives not to 'stack' people who are unfamiliar to each other.

Harper et al. (2002) suggested that training efforts become effective when they are in line with the needs, ideas and aspirations of the trainees. Moreover, Tegegne and Meheret (2010) noted the inability of short trainings to impart necessary skills to the trainees. However, in opposition to these ideal conditions, failure to tune trainings with the needs, priorities, and educational attainment levels of the operators, short duration of the training sessions, unjustified discrimination while selecting trainees, are among some of the training-related shortcomings narrated by the operators. Obviously, the presence of these drawbacks diminishes the effectiveness of the provided trainings. Interestingly, on the other hand, participants of the FGD pointed out that too much reliance on government for everything, lack of commitment to be changed ,lack of vision and absence of entrepreneurial spirit have contributed to their respective MSEs inability to develop and graduate fast.

Despite exhibiting some individual-related behaviors (such as lack of commitment and vision, extravagance), all the operators are literate, physically 
strong with a capacity to access medical facilities, have prior work-related experience and skill, and have good access to training with all its shortcomings. All these are fair indicators of the substantial level of $\mathrm{HC}$ possessed by the targeted operators.

\subsection{Social Capital (SC)}

$\mathrm{SC}$ is a resource embedded in social relationships, associations, networks, sharing, friendships, reciprocity and moral support. In the absence or shortage of other types of assets, SC is commonly used by the urban poor to survive on a day-to-day basis (Phillips: 2002).

The operators indicated that, despite they came from different socio-economic backgrounds; there exists a strong social bond and persistent interpersonal interaction. During the FGD and interviews, it was repeatedly indicated that the studied operators participate actively in various informal social organizations such as Idir ${ }^{6}$ and Iqub. According to the operators, the main purpose for establishing the former is to mobilize and get emotional and material support upon a death of the member himself or his relatives while the latter is a voluntary, informal, and indigenous form of rotating saving and credit scheme, where each member contributes a mutually agreed amount of money on weekly or monthly basis .In such schemes, each member is entitled to receive the collected lump sum once based on his/her contribution. The Sustainable Livelihoods perspective considers such indigenous rotating saving and credit and reciprocated support devices as constituents and examples of 'policies,

\footnotetext{
${ }^{6}$ An indigenous institutional arrangement in which members regularly contribute to a common pool (in cash or in kind) with a view to supporting a needy member. Membership can be open to all residents of a locality or could be restricted to certain categories like neighbors, women, youth, ethnic group, etc.
} 
institutions, and processes' and; are very decisive in the effort of creating, enhancing, and shielding other types of assets especially physical and social ( Harper et al : 2002). Coming back to the experience of the operators, they pinpointed that the cooperation between them even goes to the extent of exchanging tools, equipment, and sometimes labor freely, besides renting machines from each other. There are even instances where one cooperative MSE directs job orders to other cooperatives provided that it is not capable of producing the same due to various reasons. In one MSE, very uniquely, it was found out that the members always have Sunday's breakfast together. The expense of this regular Sunday accommodation is covered by the income generated from the sale of useless timber and other by-products, as an FGD participant from this MSE underscored. Most of the operators and their family members spend holidays together. This has served as cement in strengthening their already existing firm social interaction and sense of belongingness.

The operators unanimously agreed that their current work has created an opportunity to borrow money from each other, which again deepens the SC of the target group. Moreover, their engagement in MSEs has allowed them to meet, know, and introduce themselves to higher officers and lower level employees working in numerous governmental and private institutions like MFIs, banks, mass media, research institutions etc. The role and contribution of trade fairs and bazaars in creating and sustaining such social interaction was underlined by the operators.

Tegegne and Meheret (2010) wrote that horizontal and vertical cooperation are the two types of partnerships enabling and easing collective efficiency, transfer 
of innovation and opportunities for upgrading and growth among firms. The former, the same writers continued, allows similar businesses to be jointly involved in activities such as sub-contracting, purchase of raw materials, marketing and training whereas the latter denotes linkages which take a form of 'supplier-producer or input-output relations and the sub-contracting of phases of production cycles from vertical linkages'. In spite of this, it was indicated by the operators that cooperation and partnership particularly in market and raw material-related issues was weak. The absence of such collaboration has been detrimental to the MSEs as indicated by one respondent in the following manner:

We (the MSEs) are losing a great deal of money that can be used for the growth of our respective establishments. This is mainly because of our unwillingness and inability to cooperate. For instance, if we jointly purchase raw materials, we can have more negotiation and bargaining power over the suppliers. Obviously this results in substantial reduction of input prices. The money that we saved from such 'robbery' of raw material suppliers, via our cooperation, could be reinvested in our businesses. [43, Male, Married]

As empirically revealed above, there is enriched social relationship and support network in the form of Idir and Iqub, borrowing money from each other, in addition to information, equipment and tools exchanging and sharing. Likewise, the operators spend holidays together and share Sunday's breakfast. In conclusion, the operators have high level of SC. 
The Livelihoods of Micro and Small Enterprise Operators

\subsection{Physical Capital (PC)}

PC includes assets such as housing, tools and equipment that people own, rent or use and public infrastructure that they have access to (Farrington et al: 2002).

While land is generally considered as a natural capital, it is appropriate to see it as a physical asset that enables access to shelter and work premises in addition to having locational significance that provides access to other livelihood opportunities and investment potential (Payne: 2002). In this study, the urban land on which either the residences of the operators or their working shades are constructed was addressed in relation to its location and tenure security by the target group. Accordingly, most of the operators speculated that the central location of the land on which the homes of most operators are built, on top of being tenants of houses owned by the kebele, worsened the insecurity of tenure of the operators. According to the key informants, Lideta is one of the subcities of Addis Ababa where massive large scale urban renovation and redevelopment projects are currently undertaken. Therefore, it is not surprising if all dwellers especially poor tenants residing in these central areas feel a risk of eviction and relocation with all its negative consequences on their livelihoods. Most of the approached interviewees reported that their houses are not livable. According to them, the same is true for their immediate environmental situations. The reported bad housing condition can be taken as a possible outcome, since the absence of real and perceived tenure security discourages tenants to maintain and improve their homes and neighborhoods. In contradiction with this appalling tenure security situation of their homes, the operators have an optimistic outlook on the tenure security of their working 
place as both their shades and the land on which the shades are erected belong to the government.

\section{Housing Conditions}

Housing is one of the crucial assets for urban poor, since it is used for both productive (earning income) and reproductive purposes in addition to serving as a shelter (Moser: 1998, cited in Meikle: 2002). In the urban context, the residential and work environment and health are needed for sustaining a means of living. Accordingly, access to water, sanitation, drainage and solid waste management turn out to be a top priority. Provision and access to sanitation, drainage, and solid waste management facilities and services has many advantages. First, it reduces the risk of exposure to water-born and related diseases. Secondly, it protects the urban environment and helps to keep the appearance of urban areas. Third, it protects prolonged use of infrastructure, and lastly it creates employment opportunity (Ali: 2002).

Both the operators and key informants said that the residential houses of almost all operators are owned by the government and are managed by the kebele administration, a body responsible for renting houses in its jurisdiction and collecting rent from the tenants. As noted above, the fact that their houses are owned by the government implies a sort of tenure insecurity to their tenants. Moreover, the same absence of tenure security can be a cause for the dilapidated nature of the dwellings of the operators, as tenure insecurity, according to Payne (1996), results in lack of interest in housing improvement and neighborhood development. The operators argued that their sense of insecurity is further fuelled as their current neighborhoods are located in one of 
the city's commercially preferable central business districts, making such areas highly attractive for private investors and developers. In relation to the physical condition of the houses, the houses are dilapidated, as indicated by the respondents, and lack basic sanitation and sewerage facilities. The FGD participants added that their surrounding neighborhoods are underserved with basic social facilities and infrastructure such as roads, transport, health and educational facilities. Lastly, an attempt was made to assess the level of ownership of the operator's household assets. The operators believe that their engagement in this activity has changed their position of household asset ownership. However, the improvement is mainly related to basic home utensils and appliances such as TV set, sofa set, radio, mobile phones and the like. This conforms to other research findings like Tegegne and Meheret (2010) and Getahun (2009).

\section{Working Place Conditions}

According to an official document from the FMSEDA (2006) and the key informants, ensuring improved access to infrastructure such as electric power, minimizing financial and time loss caused by the sparse location of these mutually supportive businesses are some of the advantages expected to be realized in locating these MSEs in the same cluster. The author observed that all the studied metal and wood work MSEs are located in one cluster.

A number of shades hosted by numerous MSEs operating in wood and metal work are located in a cluster named Sahlu Chaka, the studied cluster. The operators informed the researcher that they secured their respective shades on rental basis from the woreda MSEDO, which charges only a subsidized and 
affordable rental price. Almost all shades are supplied with basic facilities like telephone, power, toilets, etc. Whatever affordable the rent of the shades is, the researcher observed that they are constructed of temporary building materials. Moreover, the paths between the shades are very narrow. The operators pointed out that this has a risk of fire explosion and the shade becomes extremely cold during the rainy season. Similarly, this nature of the shades eases the chance of theft of properties hosted inside the shades, few operators raised during informal conversations. Added to this poor condition, it was indicated that absence of selling place has aggravated the already existing 'inadequacy and crowdedness' of the internal working space of the shades. The participants intelligently argued that lack of selling place is a direct contributor for their inadequate market hence low income of the studied MSEs. Absence of selling place obviously narrows the chance to access new customers.

The studied MSEs own a variety of working machines, equipment and tools, most of which were purchased by the loan extended from Addis MFI. Welding machine, grinder, drill machine, screw driver, hammer, chisel, wrench, brush, planes, pock shave, back saw, brace, file, meter, tri square, and clamps are some of the work-related machines and equipment owned by the studied MSEs. The presence of these machines, tools and equipment has allowed the operators to produce competitive products in terms of quality and design, in addition to helping them to save their time. In other words, the presence of these machines and tools has resulted in productivity improvement of the operators. So far, it has been contended that access to and investment in production equipment directly generates income and enhances productivity (Rakodi: 2002). 
The studied cluster and the shades in it are located very near to a river. The participants of the FGD raised that this has induced two clear problems to the MSEs and their operators. First, since the river brings waste materials from other localities of the city, the chance of those working on the sides of the river to acquire air and water-borne diseases and infections is high. Secondly, the river sides are prone to land sliding and flooding. It was raised by the operators that this has complicated the task of building a fence to protect the shades in the cluster.

Since people always look for sites with good access to livelihood opportunities, public services and amenities, location of an urban land becomes imperative in urban areas ( Payne: 2002). It is also claimed that accessibility of a location is the ease with which it can be accessed by different modes of transport (Brown and Lloyd-Jones: 2002). Divergent from these, however, the studied cluster is situated far from the main asphalt road and the condition of the road leading to the cluster from the main road is extremely poor. As it was narrated by one operator, this poor state of the road condition of the locality has culminated in high transportation service cost to the MSEs, in addition to making the cluster difficult for accessibility by the existing and potential customers.

As far as transport facilities are concerned, access to affordable and appropriate public transport is of paramount vitality in expanding the employment opportunities of the urban poor who seek inexpensive access to areas of economic and commercial activity(Brown and Lloyd-Jones: 2002). Equally, 
the importance of physical capital, especially infrastructure in enabling people to access, and directly support, income-generating activities is well recognized by writers on urban livelihoods such as Rakodi(2002). Housing which is close to employment opportunities or markets will improve residents' access to income-generating work and will reduce transport costs, which can be a significant expenditure and time-drain for the urban poor( Farrington et al : 2002). But conversely, as the location of both the residences of most of the operators and the raw material market place-mercato- is far from their working area, the operators could not benefit from reduced transport price. Correlated to this, the participants during the informal conversation told the researcher that the city-wide shortage of public transport, mainly caused by poor supply of buses and road infrastructure, has an adverse effect on their activity as the operators spent hours while waiting for buses.

In most shades owned by the studied MSEs, the researcher noticed the presence of first-aid kit filled with some basic medicines. The participants of the FGD stated that these kits help only the treatment of minor injuries, while there is a likelihood of occurrence of major injuries and fatalities since the operators work long hours with and near to heavy power-driven machines and equipment. This reality alone necessitates the need for establishing a health institution with adequate personnel and other logistics near the cluster. Nevertheless, there are no such health facilities in close proximity to the cluster, the operators pointed out.

As shown in the preceding discussion, it is found out that the dwellings of the operators were shanty, owned by the kebeles (implicitly implying tenure 
insecurity), and poorly served with sanitation facilities and other public infrastructures. Being made of temporary materials, built near a river, and having inadequate road and health facilities are some of the situations characterizing the working place of the operators. The operators were in a good possession of varieties of work-related machines, tools, and household durables.

\subsection{Political Capital (PC')}

By citing Baumann and Sinha (2001), Farrington et al. (2002, pp. 20) wrote that

the ability to influence political processes which determine decision-making and access is something which men and women can build up and draw on-and thus that, in addition to the five capital assets outlined in most SL models, political capital should be considered as a sixth capital asset. Broadly, Political Capital is defined as the ability to use power in support of political or economic positions and so enhance livelihoods.

In 2005, the Ethiopian People's Revolutionary Democratic Front (EPRDF) led government put in place the National Micro and Small Enterprise Development Strategy (MTI: 2005). A report publicized by the European Union (EU) in 2005 indicated that, in the nation-wide election held in May of the same year, the ruling party was defeated in the capital, Addis Ababa, an issue well recalled and narrated by the operators too. The operators believe that this loss of vote was a big alarm to the governing party to undertake extensive public mobilization with the grand aim of regaining its previous popularity and 
acceptance among the residents of the city. To further ensure this, according to the operators, the incumbent party has begun to employ various strategies to expand its membership base among the youth. For the purpose of strengthening the loyalty of the newly recruited members, the participants of the FGD recalled that, they were made to be organized to establish MSEs.

The operators on their part added that, due to their membership of the ruling party, they could easily approach local government officials, and are stimulated to actively participate in political, economic and other public affairs at woreda, sub-city and city levels. This accessibility and responsiveness of local government machineries to the demands of the MSEs can be taken as a fact on the ground because one can fairly assume that since the Micro and Small Enterprise Development Strategy is adopted by the EPRDF-led government, it is likely that the operators who themselves are affiliated to EPRDF would have a warm welcome by the main implementing agency, i.e. WMSEDO and other government sector offices.

It is indicated that the MSEs are supported and prioritized in relation to bidding competition and its requirement, market linkage and opportunity, training and credit provision ( Federal Micro and Small Enterprises Development Agency : 2006). All these 'favours' contribute towards realizing the viability and sustainability of the MSEs. Ultimately, the continued exposure of the MSEs to these various supports, especially the market linkage facilitates the livelihood enhancement of the operators through the income secured from the revenue enjoyed by this ready- made market created by the government. But the majority of the operators are concerned with the continuity of this overall 
government support especially in helping them to link and access more market opportunities. The participants of the FGD indicated that the support they received from the government especially in relation to the market linkage is not adequate.

On the other hand, the operators pointed out that, again due to their membership, they are frequently invited to deliberate on draft government policies and strategies. This means that they are in a position to influence political decisions than non-operators. Besides, during the FGD, few operators boldly argued that their ability and chance to enjoy all the above-indicated 'supports' and the resultant economic and political gains are rewards for their membership in the ruling party. As the operators are always keen to make certain the continuation of these advantages, the operators added that, they are committed to common party-related activities such as recruiting additional members, convincing and mobilizing the wider public during elections, taking part in rallies organized by the party they favor etc.... Therefore, the connection between the government and members of these MSEs seems a kind of 'give and take' relationship. Partly, these latter manifestations of augmented level of political capital owned by the operators appears to emanate from the strong political commitment and leadership devoted by the national government; or because of the 1995 FDRE constitution( Articles 10-44), which guaranteed a firm legal base for the due protection of basic human, political, economic, democratic, social and development rights.

In exact opposition with what is optimistically discussed above, there are some scenarios damaging the high PC' possessed by the operators. The respondents 
affirmed that this occurs when pertinent decisions related to their area of engagement, training, mode of organizing members of MSEs, and the physical location of their working premises are made by government authorities operating at various tiers. According to some operators, this could be a clear indicator of the fact that their ideas, priorities, and needs are not taken into account and, thereby, lowering the PC' of the studied operators. In general, the political capital has played critical roles in enhancing the livelihoods of the operators.

In a nut shell, as discussed empirically above, the operators have relatively better access to and level of social, political, and human assets. Although not equal to the high level of possession of these three types of assets, it is also found that the operators own a significant amount of financial and physical assets.

\section{Summary of the Way Forward}

The specific aim of this paper was to determine the operator's level and access to different kinds of assets. The FC of the MSE operators is constrained by absence of pension income and debt, few remittances, and low cash. On the other hand, the studied operators accessed credit from both formal institutions mainly Addis MFI, whose payback period and interest rate were rated as unfavorable given the market problem of the MSEs and non- formal sources such as borrowing from friends, relatives, and co-workers. It was also indicated that the operators have access to formal saving facilities like Addis MFI and indigenous saving scheme called Iqub. The study has identified possession of work skills and experience, physical health and conflict resolution skills as 
decisive aspects of the HC of MSE operators. Mixed results were identified on the SC of the operators. The promissory aspects were presence of strong social bond actualized through borrowing from each other, exchanging tools and ideas, having meals together, passing holidays together and taking part in bazaars and trade fairs. Lack of partnership and cooperation among the MSEs was a negative feature identified in relation to this capital.

The analysis of the condition of PC of the operators attested that the urban land on which both the operator's homes and working shades are erected is owned by the state- a condition that resulted in an optimistic tenure security for the shades and pessimistic future in relation to the residential dwellings. The poor state of nature of the operator's homes accompanied with increased ownership of household durables and utensils was identified. Similarly, the clustered shades, as a result of their construction from temporary building materials and their closeness to a river, are exposed to risks such as fire, flooding, security problem, and theft. On the other hand, the researcher observed a variety of machines, tools, and equipment that helped the operators to manufacture quality and competitive products. The poor road facility culminated in the inaccessibility of the cluster and increased transportation cost. The absence of health institution in close proximity to the cluster is a clear paradox, given the 'dangerous' nature of the activity of the operators. Probably uniquely added to the livelihood asset category of the operators is their enlarged PC'. Most of the contacted operators genuinely informed the researcher that they are members of the ruling party. Being so, according to the operators, has allowed them to easily access government offices, secure more chance to influence political processes as they actively participate in meetings, trainings, elections, rallies, 
public mobilization and lobbying, in addition to being able to enjoy various supports from the government like market linkage, credit access, etc.

As adequately addressed by this study, the SLF is found to be more relevant in explaining the process of asset building of MSE operators, factors facilitating the process and constraints that come across. It was empirically showed that the targeted operators have high level of SC, which could be partially explained by the long-standing Ethiopian culture of reciprocity, mutual support, exchange, social linkage and kinship. The high attention given to the sector by the government is the main factor behind the considerable PC' of the operators. It was also attested that one sort of asset affects the other and the vice versa. This study has also depicted that the SLF could be more helpful to assess urban poverty and livelihoods situation in a detailed manner, if it was applied on a specific group of the urban poor and their strategies.

If the outcomes of this livelihood strategy are sought to be desirable, the following suggestions are worth mentioning to be considered in relation to the assets of the operators:

Low market has been frequently indicated as the explanatory factor for most problems faced by the studied MSEs. Therefore, it is indispensable to alleviate this deep-rooted predicament. Some of the ways of doing so can be: Linking the MSEs with other private contractors working within or around Addis Ababa; Changing the perception of the general public through extensive awareness creation mechanisms, since private individuals are envisaged to be the main 
buyers of the products manufactured by MSEs in the long run, and providing selling and display places in areas close to the shades.

Improved provision of public infrastructure and facilities such as roads, transportation facilities to the premises of the operation area and market, etc.

Improving the safety of working areas through building the shades from durable materials, avoiding the proximity of one shade to another, and constructing fence around the cluster helps to avoid risks such as flooding, fire, theft, and land sliding.

Availing credit with affordable cost and suitable repayment terms and conditions. This may be effectuated by the elimination or easing of the unfavorable policies of banks and MFIs in a way that suits the situation and needs of MSEs. Moreover, all the supports extended by the government need to be sustainable and lasting long, not implemented in the period before or during elections.

Trainings, to be effective, must be based on the needs and priorities of the operators. Moreover, the selection of trainees must be undertaken in a fair, rational and transparent manner.

Undisputedly, the government has accorded utmost attention to the sector illustrated through availing ample market opportunities, and providing different business support services, in addition to creating a favorable policy and institutional frameworks. However, the operators are skeptical of the persistence of this government support especially in relation to market linkage. This situation, if happens as projected by the 
operators, will have an adverse effect on the viability of the MSEs.

Therefore, the sustainability of the sector should be an agenda for future researches.

\section{Acknowledgements}

This paper is extracted from "Mulugeta Yohannes. 2011. The Livelihoods Reality of Micro and Small Enterprise Operators: Evidences from Woreda 01 of Lideta Sub-city, Addis Ababa City, Ethiopia. MA Thesis in Urban Development and Urban Challenges in East Africa, Addis Ababa University, Addis Ababa, Ethiopia". The author would like to thank Yirgalem Mahiteme $(\mathrm{PhD})$ for his scholarly comments, guidance and supervision throughout the study. The support of the Norwegian government's NOMA program for covering all costs of the research is also duly acknowledged. 
The Livelihoods of Micro and Small Enterprise Operators

\section{References}

Addis Ababa City Administration Micro and Small Enterprise Development Agency (AACMSEDA). 2011. 'Inception Report on Micro and Small Enterprise Development in Addis Ababa'. Addis Ababa, Ethiopia.

Adeyemi, S.L \& Aremu, M. A. 2011. Small and Medium Scale Enterprises as A Survival Strategy for Employment Generation in Nigeria. The Journal of Sustainable Development. Vol. 4: pp. 200-206.

Ali, M. 2002. Infrastructure and Environmental Health Services. In Rakodi and Lloyd-Jones, eds. Urban Livelihoods: A People-centered Approach to Reducing Poverty. Earthscan: London.

Crang, M \& Ian, C. 2007. Doing Ethnographies, Sage Publications, London.

Daniels, L. \& Mead, D. C. 1998. The Contribution of Small Enterprises to Household and National Income in Kenya. Economic Development and Cultural Change. Vol. 47: pp. 45-71.

Daniel Woldekidan. 2007. Micro and Small Scale Enterprises and their influences in alleviating Urban Poverty in Nekemte City, Oromiya Regional State. Unpublished MA Thesis in Regional and Local Development Studies, Addis Ababa University.

David, S. \& Tacoli, C. 2010. Seeking an Understanding of Poverty that Recognizes Rural-Urban Differences and Rural-Urban Linkages. In Rakodi and Lloyd-Jones, eds. Urban Livelihoods: A People-centered Approach to Reducing Poverty. Earthscan: London.

Degefa Tolossa. 2010. Understanding the Realities of the Urban Poor and their Food Security Situation: A Case Study at Berta Gibi and Gemechu Sefer in Addis Ababa City, Ethiopia. Environment and Urbanization. Vol. 22: pp. 179-198. 
The Livelihoods of Micro and Small Enterprise Operators

Dereje Lemma. 2008. Micro and Small Scale Enterprises in the Construction Sector in Addis Ababa: The case of Gullele, Kirkos and Yeka subcities. Unpublished MA Thesis in Regional and Local Development Studies, Addis Ababa University.

Ellis, F. 1999. Rural Livelihood diversity in Developing Countries: Evidence and Policy Implications. Oversees Development Institute (ODI).

Eshetu Bekele \& Zeleke Worku.2008. Factors that Affect the Long-term Survival of Micro, Small, and Medium Enterprises in Ethiopia. South African Journal of Economics, Vol. 76: pp. 548-568.

European Union (EU). 2005. European Union Election Observation Mission Final Report on the Ethiopian 2005 Legislative Elections.

Fallavier, P., Jere, H., \& Mulenga, C. 2005. Livelihoods, Poverty and Vulnerability in Urban Zambia: Assessment of Situations, Coping Mechanisms and Constraints. Draft Document for World Bank's Poverty and Vulnerability Assessment (PVA).

Farrington, J., Ramasut, T., \& Walker, J. 2002. Sustainable Livelihoods Approaches in Urban Areas: General Lessons, with Illustrations from Indian Cities. Overseas Development Institute. Working Paper 162.

Federal Democratic Republic of Ethiopia (FDRE). 1995. The FDRE Constitution. Addis Ababa, Ethiopia.

Federal Democratic Republic of Ethiopia (FDRE). 2006. Plan for Accelerated and Sustained Development to End Poverty (PASDEP). Addis Ababa, Ethiopia.

Federal Democratic Republic of Ethiopia (FDRE).2010. Growth and Transformation Plan (GTP) 2010/11-2014/15.Volume One: Main Text. Addis Ababa, Ethiopia. 
The Livelihoods of Micro and Small Enterprise Operators

Federal Democratic Republic of Ethiopia (FDRE). 2006. Support Package for Metal and Wood Work Micro and Small Enterprises under the Micro and Small Enterprise Development Program, The Urban Development Package. Addis Ababa, Ethiopia.

Federal Democratic Republic of Ethiopia (FDRE).2005. Micro and Small Enterprise Development Strategy. Addis Ababa, Ethiopia.

Federal Democratic Republic of Ethiopia (FDRE).2007. The Urban Development and Industry Package. Addis Ababa, Ethiopia.

Federal Democratic Republic of Ethiopia (FDRE). 2010.The 2007 Population and Housing Census of Ethiopia, Results for Addis Ababa City Administration. Statistical Report. Addis Ababa, Ethiopia.

Federal Democratic Republic of Ethiopia (FDRE). 2010.The 2007 Population and Housing Census of Ethiopia, Results for Country Level. Statistical Report. Addis Ababa, Ethiopia.

Garcia, J. R. \& Maru Shete. 2010. Agricultural Credit Payment in Finote Selam Town North-western Ethiopia. The Ethiopian Journal of Business and Economics. Vol.1. No.2.pp.1-25.

Gebregiwot Ageba \& Wolday Ameha. 2006. Micro and Small Enterprises (MSEs) Finance in Ethiopia: Empirical Evidences. Eastern Africa Social Science Review. Vol. 22: pp. 63-86

Getahun Reta. 2009. The Impact of Micro and Small Scale Enterprises Development Program in Reducing Urban Poverty. Unpublished MA Thesis in Regional and Local Development Studies, Addis Ababa University.

Gomez, G.M. 2008.Do Microenterprises Promote Equity or Growth?

Evaluation Report .Woord en Daad, Gorinchem, The Netherlands. 
The Livelihoods of Micro and Small Enterprise Operators

Harper, M., Grierson, J., \& Rutherford, S. 2002.Support for Livelihood Strategies. In Rakodi, and Lloyd-Jones, eds. Urban Livelihoods: A People-centered Approach to Reducing Poverty.Earthscan: London. International Food Policy Research Institute (IFPRI). 2002.Living in the City: Challenges and Options for the Urban Poor. International Food Policy Research Institute. Washington, DC.

Kayanula, D. \& Quartey, P. 2000. The Policy Environment for Promoting Small and Medium-sized Enterprises in Ghana and Malawi. Paper No.15. Institute of Development Policy and Management, University of Manchester.

Maliti, E. \& Mneawa, R. 2008. The Role of Small Businesses in Poverty Alleviation: The Case of Dares Salaam, Tanzania. Research Report 08.2. Research on Poverty Alleviation (REPOA). Mkuki na Nyota Publishers. Dares Salaam, Tanzania.

Meikle, S. 2002. The Urban Context and Poor People. In Rakodi, and Lloyd -Jones, eds. Urban Livelihoods: A People-centered Approach to Reducing Poverty. Earthscan: London.

Meikle, S., Ramasut, T. \& Walker, J. 2001. Sustainable Urban Livelihoods: Concepts and Implications for Policy. Working Paper No. 112.

Meron Assefa. 2005.Gender Dimensions of Urban Poverty in Ethiopia: The Case of Three Kebeles in Addis Ababa. In Issues in Urban Poverty: Two Selected Papers. Forum for Social Studies (FSS). FSS Studies on Poverty No. 5, pp. 25-55. Addis Ababa, Ethiopia. Netsanet Teklehaymanot. 2009. Dynamics of Poverty in Addis Ababa: The Case of Arada, Addis Ketema and Lideta Sub cities. Forum for Social Studies (FSS). FSS Research Report No.3.Addis Ababa, Ethiopia. 
The Livelihoods of Micro and Small Enterprise Operators

Paul, I. \& Rahel Wasihun. 2010. Growth Determinants of Women-operated Micro and Small Enterprises in Addis Ababa. Journal of Sustainable Development in Africa. Vol.12.

Payne, G.1996. Urban Land Tenure and Property Rights in Developing Countries: A Review. IT/ODA.

Payne, G. 2002. Tenure and Shelter in Urban Livelihoods. In Rakodi and Lloyd-Jones, eds. Urban Livelihoods: A People-centered Approach to Reducing Poverty. Earthscan: London.

Philips, S. 2002. Social Capital, Local Networks and Community Development. In Rakodi, and Lloyd-Jones, eds. Urban Livelihoods: A People-centered Approach to Reducing Poverty. Earthscan: London.

Rakodi, C. 2002. A Livelihoods Approach-Conceptual Issues and Definitions. In Rakodi, and Lloyd-Jones, eds. Urban Livelihoods: A People -centered Approach to Reducing Poverty. Earthscan: London.

Rakodi, C. \& Lloyd-Jones, T. eds. 2002. Urban Livelihoods: A People -centered Approach to Reducing Poverty. Earthscan: London.

Rigg, J. 2007. An Everyday Geography of the Global South. Routledge: New York.

Roy, M. \& Wheeler, D. 2006. A Survey of Micro-Enterprise in Urban West Africa: Drivers Shaping the Sector. Development in Practice. Vol.16: pp. $452-464$.

Tegegne Gebre-Egziabher \& Meheret Ayenew. 2010. Micro and Small Enterprises as Vehicles for Poverty Reduction, Employment Creation and Business Development: The Ethiopian Experience. Forum for Social Studies (FSS). FSS Research Report No. 6. Addis Ababa, Ethiopia. 
The Livelihoods of Micro and Small Enterprise Operators

Vandenberg, P. 2006. Poverty Reduction through Small Enterprises: Emerging Consensus, Unresolved Issues and ILO Activities. Small Enterprise

Development Program (SEED), Job Creation and Enterprise Development Department. International Labor Organization (ILO). Working Paper No.75.Geneva, Switzerland.

Yared Amare. 2010. Urban Food Insecurity and Coping Mechanisms: A Case Study of Lideta Sub city in Addis Ababa. Forum for Social Studies (FSS). FSS Research Report No.5. Addis Ababa, Ethiopia.

Zemen. 2011. No 42. An Amharic Magazine. 